\title{
The Role of Flexibility in the Realization of Inclusive Education
}

\author{
Laura Lübke*(D), Martin Pinquart (D) and Malte Schwinger (D) \\ Department of Psychology, Child and Adolescent Psychology, Philipps University Marburg, \\ 35032 Marburg, Germany; pinquart@staff.uni-marburg.de (M.P.); malte.schwinger@uni-marburg.de (M.S.) \\ * Correspondence: laura.luebke@staff.uni-marburg.de
}

\begin{abstract}
This study focused on associations between teachers' flexibility and their use of evidencebased strategies in inclusive education in a sample of $N=119$ teachers. Flexibility showed direct effects on teachers' attitudes towards the achievement of mainstream students and students with learning difficulties, attitudes towards social benefits of inclusion for students with emotional and behavioral disturbances, and on teachers' self-efficacy regarding the support of students' social skills. Furthermore, indirect effects of flexibility on intentions and behavior regarding the support of social skills were found. The findings emphasize the importance of teachers' flexibility in the realization of inclusive education.
\end{abstract}

Keywords: flexibility; teachers; inclusion; learning difficulties; emotional and behavioral disturbances

check for updates

Citation: Lübke, L.; Pinquart, M.; Schwinger, M. The Role of Flexibility in the Realization of Inclusive Education. Sustainability 2021, 13, 4452. https://doi.org/10.3390/ su13084452

Academic Editor: Vasiliki Brinia

Received: 1 March 2021

Accepted: 14 April 2021

Published: 16 April 2021

Publisher's Note: MDPI stays neutral with regard to jurisdictional claims in published maps and institutional affiliations.

Copyright: (c) 2021 by the authors. Licensee MDPI, Basel, Switzerland. This article is an open access article distributed under the terms and conditions of the Creative Commons Attribution (CC BY) license (https:// creativecommons.org/licenses/by/ $4.0 /)$.

\section{Introduction}

In many countries, the realization of inclusive education can be seen as one of the most substantial changes in their school systems [1]. Even though inclusion is often shortened to the placement of students with disabilities or special educational needs (SEN; e.g., learning difficulties, physical disabilities) in regular classes, it goes far beyond this [1] (p. 302). A common aspect of many approaches to define inclusion is the adaptation and modification of education (e.g., to vary the complexity of tasks) based on the individual needs of students [2,3]. Therefore, in the current paper, inclusive education is defined as "a process of high-quality implementation of aspects that are important for psycho-emotional and academic development of students with and without SEN" [4] (p. 32). Following this assumption, the implementation of inclusive education significantly affects the organization of teaching. A rigid adherence to old teaching systems (e.g., providing one content which has to be learned in a specific way to present a specific result) or the stipulation that students with SEN must adapt to them lead to stagnation in the educational process and contradict the United Nations Educational, Scientific and Cultural Organization's agenda [5].

Thus, teachers' behavior plays an important role on the way towards a successful and sustainable realization of inclusion. The increasing heterogeneity and demands make it necessary that teachers are able to use a broad variety of teaching strategies, also to cope with difficult and stressful situations. In this regard, the UNESCO [6] outlined flexibility as an important competence for teachers in inclusive settings to reach an adequate education for all learners. Especially with regard to the usefulness of the study results for practice, the flexibility of a teacher appears to be a promising starting point. On the one hand, it tends to be a dispositional trait that should be stable across different situations; on the other hand, however, there are indications that it is a trait that can be promoted through appropriate interventions [7]. Therefore, the present study focuses on the impact (We are aware that these are still correlational data, so we cannot be certain about the causality of relationships. Nevertheless, due to the clear theoretical assumption that personal background factors are supposed to influence one's behavior, we deem it appropriate to use these data as a cautious starting point for interpretation of the relationships in question.) of flexibility on in-service teachers' use of evidence-based strategies in inclusive education, based on an adapted version of Ajzen's theory of planned behavior (TPB) $[8,9]$. 


\subsection{Evidence-Based Strategies}

As mentioned above, in the context of inclusive education, there is a need for teachers to deal with very different situations and diverse demands. Hence, teachers require a broad repertoire of strategies to cope with heterogeneity and challenging situations. Generally, those strategies should be evidence-based in regular and inclusive education to fit all learners [1]. In addition to this general fit, it seems reasonable that different strategies could be more or less important to support certain needs (i.e., academic or social). Focusing on specific areas of support rather than diagnosed disorders addresses the fact that even students with the same diagnosis have different needs for support in school. Students with emotional and behavioral disturbances (EBD) are characterized as having problems with their attention span and concentration, showing disruptive behavior and having problems in the relationship with peers and adults [10]. This shows clear overlaps in terms of symptomatology, especially with attention-deficit hyperactivity disorder (ADHD). Even though not all students with ADHD are labeled as having SEN, studies show a high prevalence of comorbidity between ADHD and EBD [11]. Therefore, results regarding students with EBD might be highly relevant for the successful education of students with ADHD. However, there are also many students with ADHD who have learning difficulties (LD) [11]. Thus, depending on the prevailing need of support, the results with respect to students with LD may also be of importance when it comes to classroom support for students with ADHD.

To address these different needs, the following section describes evidence-based strategies that focus either on students' academic or social skills.

\subsubsection{Support of Learning Skills}

Throughout the process of teaching and learning, it is important that learners develop techniques, which help them learn efficiently and effectively. According to Mitchell [1], these strategies can either be general (e.g., self-regulated learning) or specific concerning their appropriateness to a particular task (e.g., the mnemonic POSSE (predicting, organizing, searching, summarizing, evaluating) for reading organization). The support of useful skills to improve the learning process is essential, especially for students with LD [1]. Children with LD generally experience problems in the academic domain, e.g., in learning to write or acquiring general study skills [10,12]. To provide guidance to students with SEN in the field of learning, teachers need to support strategies concerning the organization and integration of information in different kinds of tasks [1,13] (p. 93).

\subsubsection{Support of Social Skills}

Beside the development of efficient and effective learning, the experience of positive interaction with others is an important aspect of children's school life. If children lack social skills, they are at risk of a low social status, poor achievement, etc. [14,15]. Especially students with EBD need support in establishing social skills [1]. By controlling the antecedents (e.g., classroom climate) and consequences (e.g., reinforcement of desirable behavior through a behavior-support plan), children can learn how to react in an appropriate way [1]. Therefore, in the context of inclusion it seems essential for teachers to know such behavioral management strategies.

However, studies show that teachers do not necessarily base their choice of support strategies on their empirical effectiveness [16] and that reactions to challenging behavior are often inappropriate [17]. The use of ineffective or inappropriate strategies could lead to lessons being perceived as stressful and unsatisfactory by both teachers and students. In order to promote quality teaching for all students, it therefore seems particularly important to identify factors that make the use of evidence-based strategies more likely. 


\subsection{Theory of Planned Behavior}

According to the TPB [8], peoples' intentions to behave in a specific manner are predicted by their attitudes towards this behavior, their control beliefs, and the social pressure they feel (subjective norms) [8].

In fact, studies showed associations between attitudes towards the inclusion of students with SEN and different behavioral outcomes. In the case of inclusive education, they represent teachers' perceptions of positive (e.g., increasing social skills of students without SEN) and negative (e.g., a decreasing academic performance of students without SEN) outcomes caused by an inclusion of students with SEN in regular classrooms. For example, Monsen, Ewing, and Kwoka [18] found that teachers' attitudes towards the inclusion of students with SEN have a significant impact on the management of the learning environment and students' satisfaction with learning. In general, attitudes towards inclusion tend to negative [19] and vary by types of SEN [20,21]. Furthermore, positive attitudes towards inclusion are associated with higher self-efficacy expectations [22].

In the TPB self-efficacy expectations are represented by control beliefs [23]. Control beliefs are defined as the belief of being successful in performing certain behavior [23]. The teachers' beliefs regarding their teaching-ability and their impact on students' learning outcomes are associated with effective instructions, better classroom management [24], and better academic performance of students $[25,26]$. In addition to self-efficacy expectations, an external locus of control can have an effect on a person's actual behavior [9]. However, teachers with lower levels of self-efficacy expectations tend to believe that external factors hinder them in supporting students' academic achievement [27]. This leads to the assumption that this theoretical aspect is already covered by the assessment of self-efficacy. Therefore, the current study assessed control beliefs solely via teachers' self-efficacy expectations. Because the staff of a certain school represents a relatively stable group with certain behavioral norms, the expectations of the social environment should play a role in addition to the expectations regarding one's own abilities. According to the TPB, the perceived behavioral norms (i.e., supporting the implementation of inclusive education) create a social pressure which increases the motivation to perform the given behavior (i.e., using strategies to support the development of learning and social skills [28]). These subjective norms depend on a person's beliefs about the expectations of important others and the motivation to fulfil those expectations [8]. It seems reasonable that for teachers those important others may be their colleagues.

\subsection{Flexibility}

There is evidence for relationships between certain background factors and individual components of the TPB (e.g., differences in attitudes depending on the school track in which a teacher is working) [29]. In recognizing the potential of certain factors, which are supposed to influence a person's attitudes and expectations, Ajzen [9] added personal, social, and information background factors to his initial model. Thereby, he assumed mediating effects through the TPB components on the behavior [9].

In the current study, we focus on personal background factors, as it is known from innovation research that individual characteristics have an important impact on innovative behavior [7]. Studies in the field of innovation processes, defined as changing job-related demands (e.g., the implementation of inclusive education), showed that a person's tendency to refuse any change can get in the way of innovation [30]. This rigidity as an inflexible and maladaptive behavior can lead to resistance and makes adjustment to change difficult [31]. In reverse, flexibility should enable a teacher to find diverse solutions for coping with challenging situations (e.g., different ability levels or inappropriate behaviors) in the classroom.

Flexibility can be defined as "the capacity to change and to adapt to a challenging environment" [7] (p. 166). Furthermore, Georgsdottir and Getz [7] also distinguish between adaptive and spontaneous flexibility. Adaptive flexibility enables a person to shift his or her perspective on an occurring problem and to use new strategies if the existing methods 
no longer work. Spontaneous flexibility describes a person's tendency to search for various ways to deal with a problem without external pressure [7]. Many teachers perceive the implementation of inclusive education as a challenging change of job-related demands [32]. To cope with this external pressure "to adapt to a challenging environment" [7] (p. 166) adaptive flexibility may be a useful ability for teachers [30,31]. Indeed, an older study by Ekstrom [33] showed a positive impact of teachers' flexibility on the complexity of their classroom organization and their ability to react differentially to students' needs. Furthermore, a broad variety of coping resources may have a positive effect on the teacher's self-efficacy beliefs (i.e., "the evaluation of their abilities to bring about positive student change" [27] (p. 570)) and thereby facilitate the use of diverse teaching practices instead of stocking in a narrow range of old behavioral patterns.

In addition, there might be an association between flexibility and attitudes. It seems reasonable that inflexible persons (i.e., with an aversion towards any change) may overestimate the costs of an innovation (i.e., a possible decline of the academic standard in the case of inclusive education) because they cannot find as many solutions for potentially arising problems as flexible persons can. Following this assumption, a low level of flexibility is supposed to lead to a negative evaluation, and therefore, to more negative attitudes towards the inclusion of students with SEN.

Although teachers' flexibility seems to be an important factor regarding the realization of inclusive education, there is little evidence available in support of this assumption. Existing studies on flexibility have focused on different contexts (e.g., technology acceptance) or on selected aspects (e.g., effects on the complexity of classroom organization). There remains a need for a theory-driven investigation of the psychological mechanisms through which teachers' flexibility affects the realization of inclusive education $[9,23,27]$.

\subsection{The Current Study}

We seek to examine the impact of teachers' flexibility on their attitudes towards inclusion and their self-efficacy beliefs, which in turn are supposed to predict (together with the subjective norms) their intentions and behavior regarding inclusive education. Because of the fact that attitudes towards inclusion vary depending on the type of SEN, we specified two different models (i.e., differentiating between LD and EBD, as well as between the corresponding forms of support of these special needs) based on the TPB [9]. As described above, in the current study, attitudes were conceptualized as the summative evaluation of the likely consequences of inclusive education. Thus, they reflect the teachers' assumptions about whether inclusion is a promising educational concept or not. If a teacher assumes that inclusive education in general cannot create positive outcomes (academically or socially) he/she might also hold lower expectations regarding his/her own possibilities to create a supportive learning environment for all students. In this study, these selfefficacy expectations were represented by teachers' beliefs regarding their own ability to successfully implement supportive strategies on the basis of the given resources and obstacles [34]. As a result, they are conceptually more closely related to intentions and behavior than the more general attitudes. Therefore, in this study, we assumed a direct statistical effect of self-efficacy expectations on intentions according to the TPB. Contrary to the assumptions of the original model, however, we suppose that the effect of attitudes on intentions and behavior to be mediated by teachers' sense of efficacy.

\subsubsection{Model 1: Model with Focus on Learning Difficulties and Support of Learning Skills}

We assumed that flexibility has a direct effect on teachers' attitudes towards the achievement of mainstream students and students with LD in inclusive classrooms and their self-efficacy concerning the support of learning skills. Furthermore, flexibility should have an indirect effect on teachers' intentions and self-reported behavior to support learning skills. We expected a direct effect of attitudes on self-efficacy beliefs, as well as indirect effects on intentions and self-reported behavior. In addition, indirect effects of subjective 
norms and self-efficacy on self-reported behavior were assumed, as described in the TPB [9]. In order to adequately consider the original TPB model, its fit to the data was also tested.

1.4.2. Model 2: Model with Focus on Emotional and Behavioral Disturbances and Support of Social Skills

In line with the model concerning LD, we assumed that flexibility has a direct effect on teachers' attitudes towards social benefits of inclusive education for mainstream students and students with EBD, their self-efficacy concerning the behavior management strategies, and the attitudes teachers suppose from their colleagues. In addition, flexibility should have an indirect effect on teachers' intentions and self-reported behavior to use behavior management strategies. Like in the LD model, we expected a direct effect of attitudes on self-efficacy beliefs, as well as indirect effects on intentions and self-reported behavior. Furthermore, we assumed the same indirect effects of subjective norms and self-efficacy as in the LD model. Here, too, the original model was checked for its fit.

\section{Materials and Methods}

\subsection{Participants}

A sample of 119 in-service teachers from different parts of Germany participated in this study either using an online $(n=62)$ or a paper-pencil questionnaire $(n=57)$. The participants were recruited either directly via the respective schools or via relevant online forums. Overall, $82 \%$ of the participants were female (national average for the school year 2019/2020: 73.1\%) [35]. The mean age was 42 years $(S D=12.99$; range $=24-66)$, and the mean work experience was 15 years $(S D=13.01$; range $=0.5-43)$. Because the focus of the study is on strategies that are appropriate for supporting both students with and without special needs, teachers from all types of schools were included in the study. About $46 \%$ of the teachers worked at primary schools (national average for the school year 2019/2020: 30\%) [35], 51\% at secondary schools (national average for the school year 2019/2020: 57\%) [35], and 3\% at a special school for students with SEN (national average for the school year 2019/2020: 10\%) [35]. Furthermore, 59\% of the participants reported experiences in teaching students with SEN in inclusive classrooms.

\subsection{Procedure and Sequence of the Survey}

In Baden-Wuerttemberg, on-site surveys were conducted in 15 schools (with the approval of the responsible Ministry of Education and Cultural Affairs). Furthermore, the online tool SosciSurvey (https:/ / www.soscisurvey.de/, accessed on 15 April 2021) was used to provide the online version of the questionnaire. The link leading to the survey was distributed via a newsletter for teachers and via teacher-specific groups in social networks or Internet forums.

In both the online and paper versions of the questionnaire, detailed information was provided on the first page about the purpose of the study, the handling of the data collected, and the possibility of dropping out of the study at any time without giving reasons. The questionnaire used captured constructs associated with teacher behavior in addition to sociodemographic information (see Measures Section for details). At the end of the survey, teachers could subscribe for being informed of the study results.

Data collection took place in August and September 2016 and from March to May 2017.

\subsection{Measures}

\subsubsection{Flexibility}

Flexibility was assessed with the respective subscale ("Flexibilität") of the Bochumer Inventar zur berufsbezogenen Persönlichkeitsbeschreibung (BIP) [36]. The BIP measures personality traits with a focus on work contexts. The flexibility scale captures the ability and willingness to adapt to changing conditions in the professional context (e.g., "I prefer to work on tasks where I can estimate what to expect." (reversed)). The subscale consisted of 14 items, which were answered on a 6-point scale ranging from 1 (fully applies) to 6 
(does not apply at all). The internal consistency of the present study $(\alpha=0.87)$ is in line with previous findings for this scale $(\alpha=0.87)$ [36].

\subsubsection{Attitudes}

Attitudes towards inclusion were assessed by the means of the subscales of the Differentiated Attitudes Towards Inclusion Scale (DATIS) [21,37]. The four subscales measure attitudes towards (1) the achievement of mainstream students in inclusive classrooms ("Achievement Mainstream Students" (MS), six items), (2) the achievement of students with SEN in inclusive classrooms ("Achievement SEN", five items), (3) the social benefits of inclusion for mainstream students ("Social Benefits MS", four items), and (4) the social benefits of inclusion for students with SEN ("Social Benefits SEN", four items). The dimensional structure could be replicated with different samples of student and in-service teachers of various school types. The DATIS turned out to have a good construct and divergent validity as well as satisfactory reliabilities [21]. All items were answered on a 4-point scale ranging from 1 (totally disagree) to 4 (totally agree). In the current study, the subscales regarding the achievement (Achievement MS, Achievement SEN) were used with a focus on the inclusion of students with LD. The subscales focusing on the social benefits of inclusive education (Social Benefits MS, Social Benefits SEN) were used with respect to the inclusion of students with EBD. Internal consistencies of the present study are in line with previous research [21] and can be considered as good $(\alpha=0.82-0.90)$.

\subsubsection{Subjective Norms}

The teachers' perceptions of their colleagues' attitudes towards inclusion were assessed by the mean of a questionnaire with four items by Lübke et al. [37] (e.g., "My colleagues think inclusion is important."). The items were constructed using the TPB [23]. All items were answered on a 4-point scale ranging from 1 (totally disagree) to 4 (totally agree). The internal consistency of the present study can be considered as good $(\alpha=0.84)$.

\subsubsection{Self-Efficacy, Intention, and Behavior}

The expectations regarding the successful use of teaching strategies, the willingness to use them and the self-reported frequency of strategy use were assessed by an aggregation over different strategies, which either support the development of students' learning (cognitive strategy instruction, memory strategies and self-regulated learning) or social skills (behavioral approaches, functional behavioral assessment, promotion of positive classroom climate, reactions to disruptive behavior, and social skills training). All strategies showed empirical evidence for mainstream students as well as for students with SEN [1,38]. The aggregated scores regarding the support of learning skills were used in model 1 (LD), whereas the scores regarding the support of social skills were used in model 2 (EBD). All items (self-efficacy/intentions/frequency) were answered on a 4-point scale ranging from 1 (totally disagree/not willing at all/very rare or never) to 4 (totally agree/very willing/very often). An example is displayed in Figure A1 in Appendix A. The scales regarding the support of students' social skills (SS) showed good internal consistencies for the current study $(\alpha=0.80-0.82)$. The internal consistencies for the scales concerning the support of learning skills (LS) were not satisfying for the current study $(\alpha=0.56-0.68)$, which could be because of the small number of items (three items). A hypothetical extension of the scales to five items (like the scales regarding the support of social skills), using the Spearman-Brown correction, would raise the internal consistencies to a satisfying level ( $\alpha=0.71-0.81)$ [39].

\subsection{Statistical Analyses}

All statistical analyses (except for the computation of Cronbach's alpha) were performed with Mplus 7 with a full information likelihood (FIML) estimator to deal with missing data. At first, intercorrelations between and reliabilities of the assessed scales were shown. Linear path analysis with Mplus7 was used to display, calculate, and check complex relationships between variables. The expected indirect effects were examined using 
the bootstrapping procedure implemented in Mplus 7 with 5000 bootstrapped samples. Bootstrapping generates an empirical approximation of the sampling distribution of the statistic over many bootstrap resamples, which is used for hypothesis testing [40]. For fit indices, the Chi-squared tests, the comparative fit index (CFI; should be higher than 0.95, best above 0.97 ), the root-mean-square error of approximation (RMSEA; should be under 0.05), and the standardized root-mean-square residual (SRMR; should be under 0.05) were used [40]. First, the original TPB models were tested. Second, the hypothesized models (see Sections 1.4.1 and 1.4.2) were specified.

\section{Results}

\subsection{Descriptive Statistics}

Table 1 displays scale means, reliabilities, values of skewness and kurtosis, and intercorrelations. Overall, the correlations between the attitude scales and the self-efficacy scales are in line with previous research [41]. However, the attitudes concerning the social benefits of inclusive education of students with EBD for mainstream students (Social Benefits MS) showed no relationship with the self-efficacy beliefs regarding the support of students' learning skills (Self-Efficacy LS). With regard to skewness and kurtosis, there were hardly any significant deviations from the normal distribution. However, conspicuous values were found with regard to the scale for the frequency of the use of strategies to promote social skills (frequency SS: skewness: -0.85; kurtosis: 1.20). Visual inspection of the distribution of values confirmed an accumulation of values in the upper range of the scale. The skewness of the scale on attitudes towards social benefits of inclusion of students with EBD for students without SEN also showed a slightly higher value (-0.48), which might be due to the sample size [42].

\subsection{Model 1: Model with Focus on Learning Difficulties and Support of Learning Skills}

First, the original TPB model was tested, in which intentions were additionally predicted by attitudes $\left(\chi^{2}=11.78, d f=7, p=0.11 ; \mathrm{CFI}=0.97\right.$; RMSEA $=0.08,90 \% \mathrm{CI}(0.00,0.15)$; SRMR $=0.05$ ). As expected, no effect from attitudes on intentions was found (AMS: $\beta=-0.02, p=0.82$; ASS: $\beta=0.08, p=0.30$ ). Based on these results, as well as on the theoretical assumptions described in Section 1.4, the following descriptions refer to the modified model.

To test the hypothesized model, a path diagram was specified, in which frequency of strategies supporting students' learning skills was predicted by the intentions to use those strategies. Intentions (support of learning skills) were predicted by self-efficacy beliefs (support of learning skills) and subjective norms. Self-efficacy beliefs were predicted by attitudes towards the achievement of mainstream students and students with LD in inclusive classrooms as well as by flexibility (see Figure 1). Indirect effects of flexibility and attitudes on intentions and frequency as well as indirect effects of subjective norms and self-efficacy on frequency were specified.

The specified model showed a good model fit $\left(\chi^{2}=12.92, d f=9, p=0.17\right.$; CFI = 0.98; RMSEA $=0.06,90 \% \mathrm{CI}(0.00,0.13) ; \mathrm{SRMR}=0.05)$. Results showed a significantly positive path from intentions to frequency of strategy use $(\beta=0.34, p<0.01)$, from self-efficacy to intentions $(\beta=0.65, p<0.01)$, and from attitudes towards the achievement of mainstream students to self-efficacy $(\beta=0.26, p=0.03)$. As expected, the beta-coefficients for the direct paths from flexibility to attitudes towards the achievement of mainstream students $(\beta=0.28, p<0.01)$ and students with $\operatorname{LD}(\beta=0.24, p<0.01)$ were statistically significant as well. Additionally, as expected, attitudes towards the achievement of mainstream students showed an indirect effect on intentions $(\beta=0.17, \mathrm{CI} 95 \%(0.03,0.31), p=0.02)$, which was mediated by self-efficacy. Furthermore, the indirect effect from self-efficacy to frequency reached statistical significance $(\beta=0.22, \mathrm{CI} 95 \%(0.09,0.35), p<0.01)$. The total indirect effect from flexibility to intentions reached statistical significance $(\beta=0.12, \mathrm{CI} 95 \%$ $(0.01,0.25), p=0.04)$, whereas the specific indirect effects did not. However, the specific indirect effect from flexibility to intentions mediated by attitudes towards the achievement 
of mainstream students and self-efficacy showed statistical significance on a $10 \%$ level $(\beta=0.05, \mathrm{CI} 90 \%(0.01,0.09), p=0.05)$. Contrary to our assumptions, there were no indirect effects of flexibility on frequency of strategy use (total indirect effect: $\beta=0.04, \mathrm{CI} 95 \%$ $(-0.01,0.10), p=0.10)$. All results are displayed in Figure 1 and Table A1 in Appendix A.

\subsection{Model 2: Model with Focus on Emotional and Behavioral Disturbances and Support of Social Skills}

First, the original TPB model was tested, in which intentions were additionally predicted by attitudes $\left(\chi^{2}=12.41, d f=7, p=0.09\right.$; CFI $=0.98$; RMSEA $=0.08,90 \%$ CI $(0.00$, $0.15)$; SRMR $=0.04)$. As expected, no effect from attitudes on intentions was found (SMS: $\beta=-0.00, p=0.98$; SSS: $\beta=0.01, p=0.83$ ). Based on these results, as well as on the theoretical assumptions described in Section 1.4, the following descriptions refer to the modified model.

To test the hypothesized model, a path diagram was specified, in which frequency of strategies supporting students' social skills was predicted by the intentions to use those strategies. Intentions (social skills) were predicted by self-efficacy beliefs (social skills) and subjective norms. Self-efficacy beliefs were predicted by attitudes towards benefits of inclusive education for mainstream students and students with EBD, as well as by flexibility (see Figure 2). Indirect effects of flexibility and attitudes on intentions and frequency, as well as indirect effects of subjective norms and self-efficacy on frequency, were specified.

The specified model showed a good model fit $\left(\chi^{2}=12.47, d f=9, p=0.19 ; \mathrm{CFI}=0.99\right.$; RMSEA $=0.06,90 \%$ CI $(0.00,0.13)$; SRMR $=0.04)$. Results showed a significantly positive path from intentions to frequency of strategy use $(\beta=0.73, p<0.01)$ as well as from selfefficacy to intentions $(\beta=0.83, p<0.01)$ and from attitudes towards social benefits of inclusion for mainstream students to self-efficacy $(\beta=0.20, p=0.05)$. As expected, the beta-coefficients for the direct paths from flexibility to attitudes towards social benefits of inclusion for students with $\operatorname{EBD}(\beta=0.30, p<0.01)$ and self-efficacy $(\beta=0.19, p=0.04)$ were statistically significant as well. Additionally, as expected, attitudes towards social benefits of inclusion for mainstream students $(\beta=0.17, \mathrm{CI} 95 \%(0.01,0.33), p=0.04)$ and flexibility $(\beta=0.16$, CI 95\% $(0.01,0.30), p=0.04)$ showed indirect statistical effects on intentions, which were mediated by self-efficacy.

Furthermore, the indirect effects from flexibility $(\beta=0.11, \mathrm{CI} 95 \%(0.01,0.22), p=0.04)$, attitudes towards social benefits of inclusion for mainstream students $(\beta=0.12, \mathrm{CI} 95 \%$ $(0.01,0.24), p=0.04)$ and self-efficacy $(\beta=0.61, \mathrm{CI} 95 \%(0.51,0.70), p<0.01)$ to frequency reached statistical significance. All results are displayed in Figure 2 and Table A1 in Appendix A. 
Table 1. Means, standard deviations, reliabilities, and correlations of all scales.

\begin{tabular}{|c|c|c|c|c|c|c|c|c|c|c|c|c|c|c|}
\hline Scale & $\alpha$ & $M(\mathrm{SD})$ & Skewness/Kurtosis & (1) & (2) & (3) & (4) & (5) & (6) & (7) & (8) & (9) & (10) & (11) \\
\hline Flexibility $^{\mathrm{a}}(1)$ & 0.87 & $3.45(0.77)$ & $-0.10 / 0.35$ & - & & & & & & & & & & \\
\hline \multicolumn{15}{|l|}{ Attitudes } \\
\hline Achievement MS a (2) & 0.90 & $2.67(0.74)$ & $-0.02 /-0.54$ & $0.31 * *$ & - & & & & & & & & & \\
\hline Achievement LD a (3) & 0.82 & $2.28(0.61)$ & $0.21 /-0.31$ & $0.27^{* *}$ & $0.43^{* *}$ & - & & & & & & & & \\
\hline Social Benefits MS (4) & 0.89 & $2.82(0.70)$ & $-0.48 * / 0.14$ & 0.07 & $0.24^{* *}$ & $0.37 * *$ & - & & & & & & & \\
\hline Social Benefits EBD (5) & 0.83 & $2.57(0.64)$ & $0.32 /-0.16$ & $0.32 * *$ & $0.40^{* *}$ & $0.45^{* *}$ & $0.40 * *$ & - & & & & & & \\
\hline Subjective Norms ${ }^{\mathrm{b}}(6)$ & 0.84 & $2.30(0.58)$ & $0.34 / 0.10$ & 0.08 & $0.42^{* *}$ & $0.39 * *$ & $0.26^{* *}$ & $0.31^{* *}$ & - & & & & & \\
\hline Self-Efficacy LS a (7) & 0.68 & $2.75(0.63)$ & $0.08 /-0.43$ & $0.21 *$ & $0.36^{* *}$ & 0.26 ** & 0.01 & $0.31^{* *}$ & $0.20 *$ & - & & & & \\
\hline Intention LS a (9) & 0.65 & $2.96(0.55)$ & $0.02 /-0.10$ & $0.28^{* *}$ & $0.25^{* *}$ & $0.25^{* *}$ & 0.16 & $0.26^{* *}$ & $0.21 *$ & $0.66^{* *}$ & $0.36^{* *}$ & - & & \\
\hline Intention SS a (10) & 0.81 & $3.33(0.48)$ & $-0.36 /-0.31$ & $0.28^{* *}$ & $0.28^{* *}$ & 0.25 ** & $0.22 *$ & 0.21 * & 0.17 & 0.17 & $0.83^{* *}$ & $0.41 * *$ & - & \\
\hline Frequency LS (11) & 0.55 & $2.61(0.61)$ & $-0.16 /-0.14$ & $0.24^{* *}$ & 0.00 & 0.05 & 0.05 & 0.09 & -0.08 & $0.22 *$ & -0.02 & 0.34 ** & 0.07 & - \\
\hline Frequency SS (12) & 0.79 & $\begin{array}{l}30.12 \\
(0.56)\end{array}$ & $-0.85^{* *} / 1.20^{* *}$ & $0.21 *$ & 0.12 & 0.16 & 0.04 & 0.00 & 0.02 & -0.01 & $0.58^{* *}$ & $0.19 *$ & $0.73^{* *}$ & 0.31 ** \\
\hline
\end{tabular}

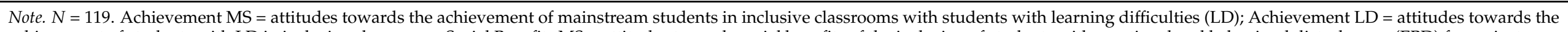

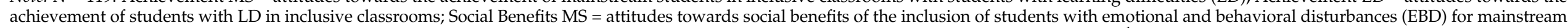
students; Social Benefits EBD = attitudes towards social benefits of inclusion for students with EBD; LS = learning skills; $\mathrm{SS}=$ social skills. ${ }^{\text {a }} N=118,{ }^{\mathrm{b}} N=116 .{ }^{*} p<0.05,{ }^{* *} p<0.01$. 


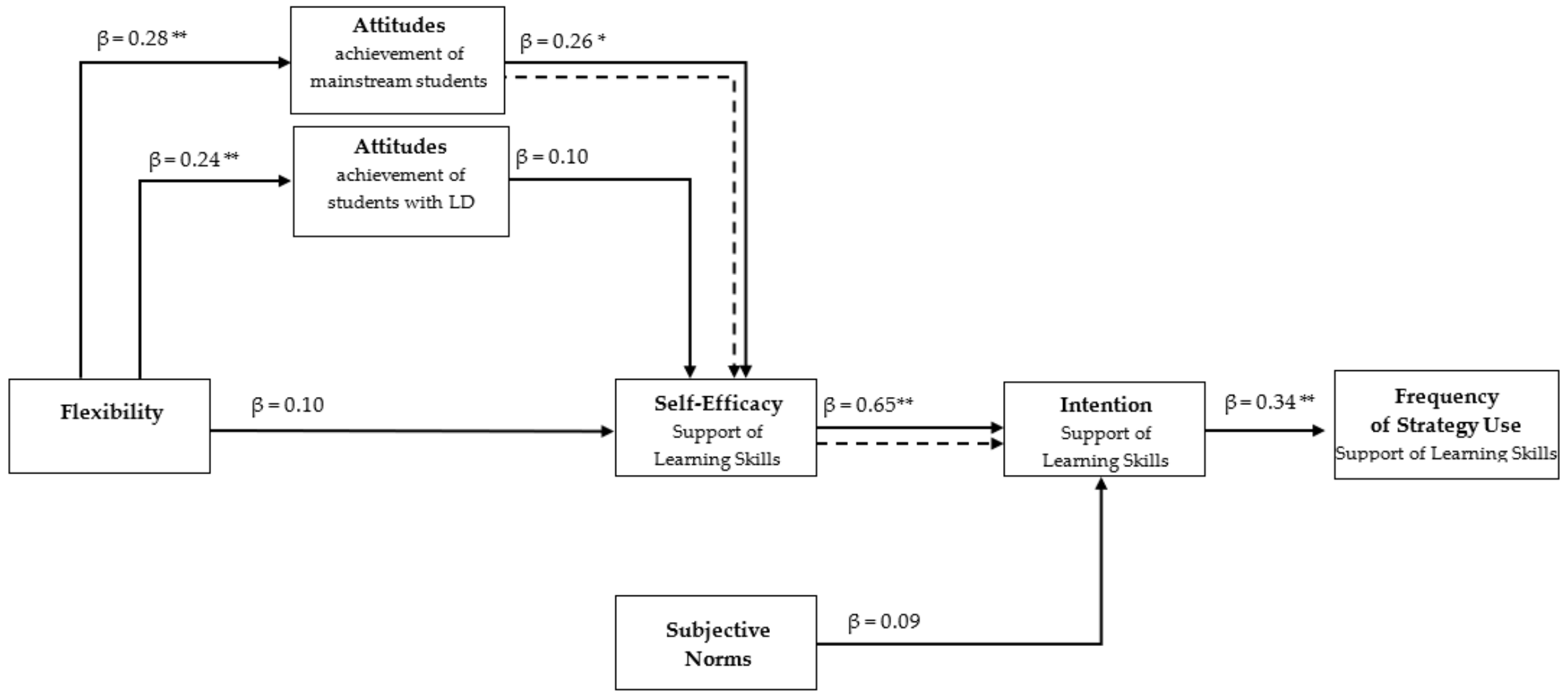

Figure 1. Structural equation model of model 1 with a focus on learning difficulties (LD) and support of learning skills. Dashed lines represent significant indirect effects. * $p<0.05$. ** $p<0.01$. 


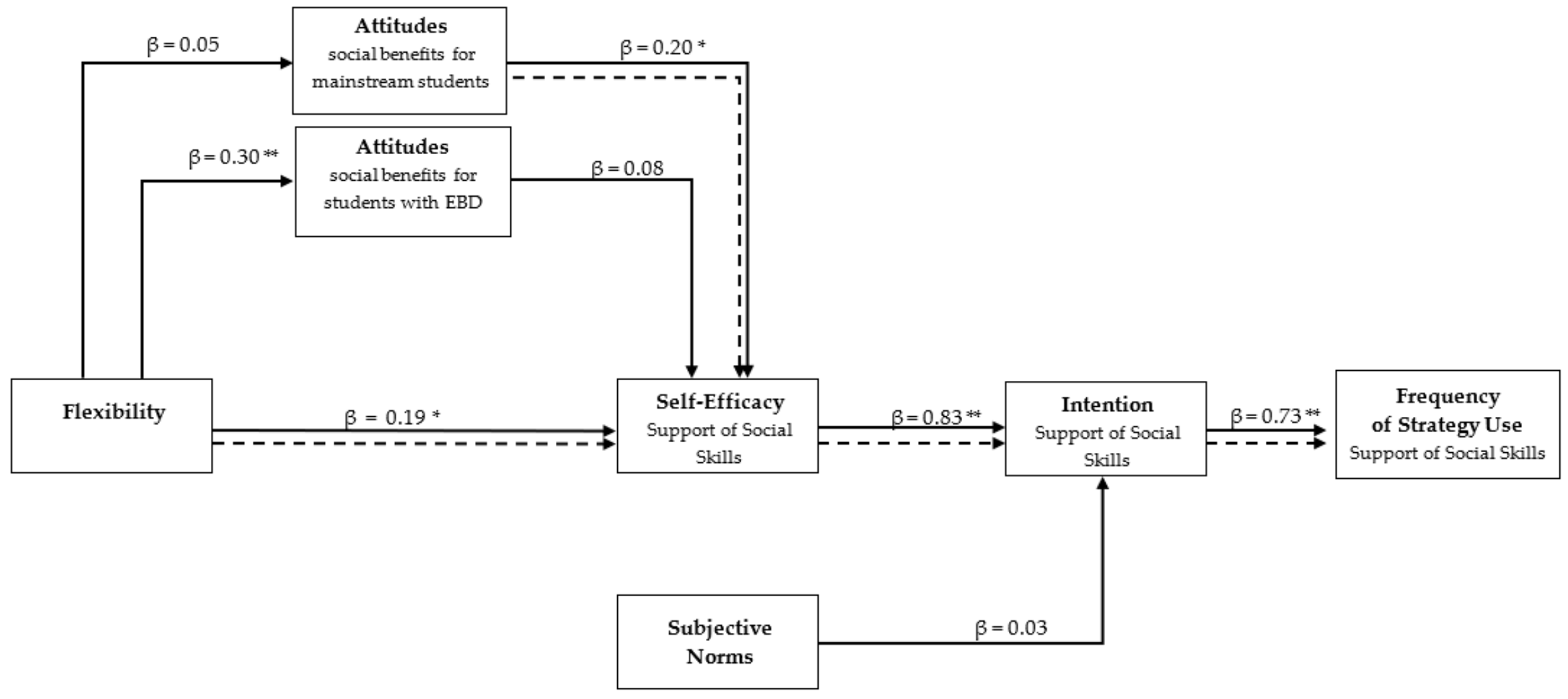

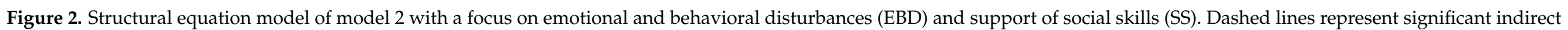
effects. ${ }^{*} p<0.05$. ${ }^{* *} p<0.01$. 


\section{Discussion}

The purpose of the current study was to examine the role of teachers' personal flexibility in the prediction of their use of teaching strategies, supporting the implementation of inclusive education. To ensure conclusive results, two models were computed for two subsets of strategies.

\subsection{Model 1: Model with Focus on Learning Difficulties and Support of Learning}

The first model explained the intention to use and the self-reported use of strategies supporting the students' learning skills by personal flexibility, attitudes towards the inclusion of students with LD, subjective norms, and self-efficacy beliefs. In this model, the effects of flexibility were rather small. Although there was a statistically significant total indirect effect of flexibility on intention, this was mainly due to the specific indirect effect of flexibility on intention mediated through attitudes and self-efficacy expectations. However, this specific indirect effect was so small that it did not reach statistical significance at a $5 \%$ level. This may be because of the rather small sample size. Since even small effects can be quite relevant in practice, studies with larger samples should be realized. Thus, there are initial indications that flexibility seems to play a role in explaining the intention to use strategies to support students' learning skills, but no further conclusions can be drawn in this respect on the basis of the present study. There was no effect of flexibility on teachers' behavior in supporting their students' learning skills.

As expected, flexibility showed positive statistical effects on teachers' attitudes towards the achievement of mainstream students and students with LD. This means that teachers, who are more flexible with regard to their job requirements, expect more positive outcomes of inclusive education concerning the academic achievement of students with and without LD. It seems reasonable that teachers who are more flexible in their conception of teaching can imagine different ways to assist their students in reaching the intended learning outcomes [7]. Hence, they may expect more positive outcomes for all of their students. As expected, the actual use of strategies supporting students' learning skills was predicted by the intentions to use them, and indirectly via self-efficacy beliefs concerning those strategies. This is consistent with results of other studies that have investigated the influence of self-efficacy expectations on teachers' behavior and instructional quality [24].

Furthermore, attitudes towards the achievement of mainstream students had an indirect effect on the intentions mediated by self-efficacy. This indicates that teachers who do not expect negative effects on academic outcomes caused by inclusive education (i.e., the mainstream students' success should be independent from the presence of students with LD) feel more competent to support students' learning skills and are more willing to apply those strategies. This is consistent with previous findings indicating that teachers who feel a responsibility for their students' success, instead of interpreting problems as a student's failure, tend to show higher expectations and a tendency to overcome those difficulties by applying adequate teaching strategies [27]. The medium-sized effect from intentions to behavior leads to the conclusion that there may be more aspects explaining the usage of the given strategies. Perhaps flexibility does not affect behavior through self-efficacy and intentions, but instead moderates the effect of intentions on behavior. The step from putting willingness into action should be more likely for persons with higher values on flexibility. Teachers with lower values on flexibility should maintain their usual strategies instead of focusing on new ones [43]. Another explanation for the lack of statistical effects of flexibility on intentions and behavior could be that strategies supporting students' skills in memorizing, planning, and self-regulation during the learning process can be taught in a straightforward and strictly organized way. This should minimize distractions [44]. In a context without significant distractions, goals do not have to be adapted, so that there is no need for flexibility in teaching those strategies [43]. 


\subsection{Model 2: Model with Focus on Emotional and Behavioral Disturbances and Support of Social Skills}

The second model focused on strategies supporting the development of social skills. In explaining the use of strategies like consistent reactions to disruptive behavior and explicit social skills training, the effects of flexibility are more striking. Flexibility directly influenced teachers' attitudes towards the social benefits of inclusive education for students with EBD. This means that teachers who do not have difficulties adapting to changing demands expect that inclusion in a mainstream class offers students with EBD the same opportunities to make friends and to be socially integrated as in special classes. Furthermore, flexibility directly predicted teachers' self-efficacy beliefs. In contrast to the first model, flexibility predicted the intentions and the self-reported behavior mediated by self-efficacy as theoretically expected. Teachers who are able to cope with changing demands and easily adapt to varying situations feel more confident to support students' development of social skills. This leads to higher intentions and higher frequencies of strategy use. The implementation of behavior management systems is very context specific, and supporting students' social skills can be very different from the traditional understanding of teaching. Therefore, teachers need competencies that enable them to adapt easily on changing situational contexts to assist students with varying needs regarding their social behavior successfully. As the inclusion of students with EBD is generally viewed as very difficult and exhausting for teachers [45], the results of this study provide an important starting point for improvements in educating this group of students by enhancing teachers' flexibility. Georgsdottir and Getz [7] summarize that teamwork is one possibility to increase flexibility. Following this assumption, co-teaching (i.e., "teachers working together in a single physical space to deliver instruction") [38] (p. 2019) might be a facilitating factor in the context of inclusive education. Even if co-teaching aims to combine expertise to benefit all learners [1] (p. 71), it may be especially helpful for students with EBD. As team teaching respects the strength of at least two teachers (e.g., one general and one special education teacher), it provides the generation of multiple perspectives on an occurring problem, and therefore, enables the creation of diverse solutions [1]. Therefore, it should enable teachers to flexibly react to occurring needs or disruptive behaviors. Albeit there is not much research on this strategy, but results are rather promising [1]. Generally, co-teaching shows rather small effects on students' achievement $(d=0.19)$ [38]. With regard to social outcomes, a recent study showed positive effects of co-teaching on the classroom climate [46]. As students with EBD often experience peer rejection [47], this may be a promising intervention regarding social inclusion. In order to implement co-teaching successfully, it is important that framework conditions are created to support collaboration (e.g., possibilities for training, time for co-planning and reflection) [19]. A recent study even showed effects of the organization of cooperation in the school staff on attitudes and the use of differentiated instruction. Accordingly, highly dense school networks seem to be more conducive when it comes to implementing inclusive education [48].

Besides flexibility, attitudes towards social benefits of including students with EBD for mainstream students showed an indirect effect on teachers' intentions of strategy use mediated by self-efficacy. Teachers who expected positive outcomes of inclusive education for mainstream students felt more competent to support students in their social development and, therefore, were more willing to use strategies supporting this aim. It seems reasonable that positive attitudes towards a topic (i.e., inclusive education) also have a positive effect on its perceived significance. This in turn could have an impact on dealing with this area (i.e., possibilities of implementing inclusive education), and thus, lead to higher self-efficacy expectations. These findings on the relationship between attitudes and self-efficacy expectations are consistent with those reported by Li and Cheung [49] in a recent study with student teachers. In addition, teachers reported slightly higher rates of using strategies supporting the development of social skills than of learning skills. It seems reasonable that educating students with lower competencies in social interactions can be enormously stressful for teachers [45]. Perhaps this causes a higher pressure of 
implementing coping strategies to manage those students' behavior. Furthermore, in the present study, promoting self-regulated learning was included in the scale assessing the use of strategies supporting learning skills. Gaastra, Groen, Tucha, and Tucha [16] showed that this is a strategy teachers use less often compared to antecedent-based and consequence-based approaches. In addition, they showed that teachers tend to use less time-consuming strategies [16]; it would be interesting to assess in future studies which of the strategies surveyed here are perceived as less time-consuming by the teachers.

\subsection{Limitations and Suggestions for Further Research}

Altogether, the present study pointed out the role of flexibility in the prediction of using evidence-based teaching strategies to cope with the challenging task of inclusive education. The diverging results regarding varying types of strategies lend support to the need of differentiated measures to identify important factors influencing teacher's behavior. Further research should focus on the prediction of the use of strategies which support students' learning skills. The development of efficient strategies to manage and regulate one's own learning process is especially important for those students with problems in acquiring certain skills like reading or with general difficulties (e.g., the understanding of instructions), but also with a short attention span. According to Hornby [10], students with LD represent the largest group of students with SEN. Therefore, future research should investigate further predictors for the support of students' learning techniques. Neither in model 1 nor in model 2 could the subjective norm (as the perceived attitude of colleagues) be identified as a predictor of intentions and behavior. Even though this is a common result regarding studies based on the TPB $[37,41]$, it is conceivable that the perceived attitudes of the school principal, as an important link between a political and a practical level, are of greater importance. In fact, Urton, Wilbert, and Hennemann [50] found a relationship between the attitudes towards inclusion of school principals and their staff. Beside this, several studies showed an impact of the perceived attitudes of school principals on teachers' actual inclusive behavior [51,52]. Considering this, further studies should focus on the school principal when assessing subjective norms as a predictor of inclusive behavior.

When interpreting the findings of the current study, it has to be taken into account that the sample was rather small. It is important to further investigate the role of flexibility in representative samples of in-service teachers. The composition of the present sample did not correspond to the national average in all areas, which can lead to biased results. For example, teachers from primary schools were overrepresented. As the proportion of female teachers at this type of school was significantly higher than at other schools (national average for the school year 2019/2020: 89.4\%) [35], this may also have led to the higher number of women in the overall sample. As educational demands differ between primary and secondary school, it would be interesting to test the given models to explain behavior separately for teachers from different school types. For instance, the implementation of certain strategies can be made more difficult by more frequent teacher changes in secondary school teaching [16]. Furthermore, the presented results are based on correlative, self-reported data. Thus, future research should focus on experimental studies (i.e., interventional studies in which the predictors of strategy use are modified by training) to validate the assumptions of causality.

\section{Conclusions}

Taken together, the presented results have utility for researchers, practitioners, and theorists, as they explain important factors with impact on teachers' usage of strategies, which have the potential to support a successful realization of inclusive education. Flexibility showed direct effects on attitudes and self-efficacy as well as indirect effects on intentions and behavior. This knowledge regarding flexibility could be used to prepare student teachers even more specifically for school practice (e.g., by addressing flexibility as a basic competence in online self-assessments) and to strengthen efforts towards increased collaboration among school staff. 
Author Contributions: Conceptualization, L.L.; methodology, L.L.; validation, M.P. and M.S.; formal analysis, L.L.; investigation, L.L.; data curation, L.L.; writing-original draft preparation, L.L.; writing-review and editing, L.L., M.P. and M.S.; visualization, L.L.; supervision, M.P. and M.S. All authors have read and agreed to the published version of the manuscript.

Funding: This research received no external funding.

Institutional Review Board Statement: Ethical review and approval were waived for this study since no vulnerable samples are examined, and the study does not violate the physical or psychological integrity, the right to privacy or other subjective rights or the interests of study participants.

Informed Consent Statement: Informed consent was obtained from all subjects involved in the study.

Data Availability Statement: The data presented in this study are available on request from the corresponding author. The data are not publicly available due to restrictions of the responsible regional council.

Conflicts of Interest: The authors declare no conflict of interest.

Appendix A

\section{Cognitive Strategy Instruction}

Students learn how to organize information so that complexity is reduced and how to integrate newly acquired knowledge into existing knowledge structures. You help students to reflect on their tasks and to approach them efficiently and effectively by communicating problem-solving strategies.

\begin{tabular}{|c|c|c|c|}
\hline \multicolumn{5}{|c|}{ How often do you use this strategy in your classroom? } \\
\hline very rare or never & rather rare & rather often & very often \\
\hline (1) & (2) & (3) \\
\hline \multicolumn{4}{|c|}{ I am sure that I can use this strategy in teaching students with SEN. } \\
\hline I totally disagree. & I rather disagree. & I rather agree. & I totally agree. \\
\hline (1) & (2) & (3) & (4) \\
\hline \multicolumn{4}{|c|}{ How willing are you to use this strategy? } \\
\hline not willing at all & rather not willing & rather willing & very willing \\
\hline (1) & (2) & (3) & (3) \\
\hline
\end{tabular}

Figure A1. Example for the measurement of self-efficacy, intention, and behavior.

Table A1. Direct and indirect effects for the two different models.

\begin{tabular}{|c|c|c|c|c|c|c|c|c|}
\hline \multirow[b]{2}{*}{ Scale } & \multicolumn{4}{|c|}{$\begin{array}{c}\text { Focus on LD and Support of Learning } \\
\text { Skills }\end{array}$} & \multicolumn{4}{|c|}{$\begin{array}{c}\text { Focus on EBD and Support of Social } \\
\text { Skills }\end{array}$} \\
\hline & $\beta$ & $95 \%$ CI & SE & $p$ & $\beta$ & $95 \% \mathrm{CI}$ & SE & $p$ \\
\hline \multicolumn{9}{|c|}{ Direct Effects } \\
\hline \multicolumn{9}{|c|}{ Attitudes: Achievement MS/Social } \\
\hline \multicolumn{9}{|l|}{ Benefits MS } \\
\hline Flexibility & 0.28 & $0.13 / 0.44$ & 0.07 & $<0.01$ & 0.05 & $-0.13 / 0.22$ & 0.10 & 0.68 \\
\hline \multicolumn{9}{|c|}{ Attitudes: Achievement LD/Social } \\
\hline \multicolumn{9}{|c|}{ Benefits EBD } \\
\hline Flexibility & 0.24 & $0.08 / 0.40$ & 0.06 & $<0.01$ & 0.30 & $0.15 / 0.46$ & 0.07 & $<0.01$ \\
\hline \multicolumn{9}{|c|}{ Self-Efficacy (LS/SS) } \\
\hline Flexibility & 0.10 & $-0.08 / 0.28$ & 0.08 & 0.32 & 0.19 & $0.01 / 0.36$ & 0.06 & 0.04 \\
\hline
\end{tabular}


Table A1. Cont.

\begin{tabular}{|c|c|c|c|c|c|c|c|c|}
\hline \multirow[b]{2}{*}{ Scale } & \multicolumn{4}{|c|}{$\begin{array}{l}\text { Focus on LD and Support of Learning } \\
\text { Skills }\end{array}$} & \multicolumn{4}{|c|}{$\begin{array}{l}\text { Focus on EBD and Support of Social } \\
\text { Skills }\end{array}$} \\
\hline & $\beta$ & $95 \% \mathrm{CI}$ & SE & $p$ & $\beta$ & $95 \% \mathrm{CI}$ & SE & $p$ \\
\hline Attitudes & & & & & & & & \\
\hline Achievement MS/Social Benefits MS & 0.26 & $0.07 / 0.44$ & 0.10 & 0.03 & 0.20 & $0.02 / 0.39$ & 0.07 & 0.05 \\
\hline $\begin{array}{c}\text { Achievement LD/Social Benefits EBD } \\
\text { Intention (LS/SS) }\end{array}$ & 0.10 & $-0.09 / 0.29$ & 0.13 & 0.43 & 0.08 & $-0.11 / 0.27$ & 0.08 & 0.41 \\
\hline Self-Efficacy (LS/SS) & 0.65 & $0.54 / 0.75$ & 0.07 & $<0.01$ & 0.83 & $0.78 / 0.89$ & 0.07 & $<0.01$ \\
\hline $\begin{array}{l}\text { Subjective Norms } \\
\text { Frequency (LS/SS) }\end{array}$ & 0.09 & $-0.05 / 0.23$ & 0.07 & 0.21 & 0.03 & $-0.07 / 0.14$ & 0.05 & 0.56 \\
\hline $\begin{array}{c}\text { Intention }(\mathrm{LS} / \mathrm{SS}) \\
\text { Indirect Effects } \\
\text { Frequency }(\mathrm{LS} / \mathrm{SS})\end{array}$ & 0.34 & $0.18 / 0.50$ & 0.11 & $<0.01$ & 0.73 & $0.64 / 0.81$ & 0.08 & $<0.01$ \\
\hline Flexibility total indirect & 0.04 & $-0.01 / 0.10$ & 0.03 & 0.10 & 0.13 & $0.03 / 0.23$ & 0.05 & 0.01 \\
\hline $\begin{array}{l}\text { Flexibility-Self-Efficacy-Intention } \\
\text { Flexibility-Attitudes Achievement }\end{array}$ & 0.02 & $-0.03 / 0.07$ & 0.03 & 0.39 & 0.11 & $0.00 / 0.22$ & 0.06 & 0.04 \\
\hline $\begin{array}{c}\text { MS/Social Benefits } \\
\text { MS-Self-Efficacy-Intention }\end{array}$ & 0.02 & $-0.00 / 0.04$ & 0.01 & 0.10 & 0.01 & $-0.02 / 0.04$ & 0.02 & 0.72 \\
\hline $\begin{array}{c}\text { Flexibility-Attitudes Achievement } \\
\text { LD/Social Benefits } \\
\text { EBD_Self-Efficacy-Intention } \\
\text { Attitudes }\end{array}$ & 0.01 & $-0.01 / 0.02$ & 0.01 & 0.49 & 0.02 & $-0.02 / 0.05$ & 0.02 & 0.45 \\
\hline Achievement MS/Social Benefits MS & 0.06 & $-0.00 / 0.12$ & 0.03 & 0.06 & 0.12 & $0.00 / 0.24$ & 0.06 & 0.04 \\
\hline Achievement LD/Social Benefits EBD & 0.02 & $-0.04 / 0.08$ & 0.03 & 0.46 & 0.05 & $-0.07 / 0.16$ & 0.06 & 0.41 \\
\hline Self-Efficacy (LS/SS) & 0.22 & $0.09 / 0.35$ & 0.07 & $<0.01$ & 0.61 & $0.51 / 0.70$ & 0.05 & $<0.01$ \\
\hline $\begin{array}{l}\text { Subjective Norms } \\
\text { Intention (LS/SS) }\end{array}$ & 0.03 & $-0.02 / 0.08$ & 0.03 & 0.23 & 0.03 & $-0.06 / 0.11$ & 0.04 & 0.56 \\
\hline Felxibility total indirect & 0.13 & $0.01 / 0.25$ & 0.06 & 0.04 & 0.18 & $0.05 / 0.32$ & 0.07 & 0.01 \\
\hline Flexibility-Self-Efficacy & 0.06 & $-0.07 / 0.20$ & 0.07 & 0.34 & 0.16 & $0.01 / 0.30$ & 0.08 & 0.04 \\
\hline $\begin{array}{l}\text { Flexibility-Attitudes Achievement } \\
\text { MS/Social Benefits MS_-Self-Efficacy }\end{array}$ & 0.05 & $-0.00 / 0.09$ & 0.02 & 0.05 & 0.01 & $-0.03 / 0.05$ & 0.02 & 0.72 \\
\hline $\begin{array}{c}\text { Flexibility-Attitudes Achievement } \\
\text { LD/Social Benefits EBD_Self-Efficacy } \\
\text { Attitudes }\end{array}$ & 0.02 & $-0.03 / 0.06$ & 0.02 & 0.48 & 0.02 & $-0.03 / 0.07$ & 0.03 & 0.45 \\
\hline Achievement MS/Social Benefits MS & 0.17 & $0.02 / 0.31$ & 0.07 & 0.02 & 0.17 & $0.01 / 0.33$ & 0.08 & 0.04 \\
\hline Achievement LD/Social Benefits EBD & 0.07 & $-0.10 / 0.23$ & 0.09 & 0.44 & 0.07 & $-0.09 / 0.23$ & 0.08 & 0.41 \\
\hline
\end{tabular}

Note. $N=118$. Achievement MS = attitudes towards the achievement of mainstream students in inclusive classrooms with students with learning difficulties (LD); Achievement LD = attitudes towards the achievement of students with LD in inclusive classrooms; Social Benefits MS = attitudes towards social benefits of the inclusion of students with emotional and behavioral disturbances (EBD) for mainstream students; Social Benefits EBD = attitudes towards social benefits of inclusion for students with EBD; LS = learning skills; SS = social skills.

\section{References}

1. Mitchell, D.R. What Really Works in Special and Inclusive Education: Using Evidence-Based Teaching Strategies, 2nd ed.; Routledge: London, UK; New York, NY, USA, 2014; ISBN 9781136253430.

2. Loreman, T. Straight talk about inclusive education. CASS Connect. 2009, 2, 43-47.

3. Macedo, E. Equity and difference in centralized policy. J. Curric. Stud. 2013, 45, 28-38. [CrossRef]

4. Schwab, S.; Sharma, U.; Loreman, T. Are we included? Secondary students' perception of inclusion climate in their schools. Teach. Teach. Educ. 2018, 75, 31-39. [CrossRef]

5. Convention on the Rights of Persons with Disabilities: Resolution/Adopted by the General Assembly: A/RES/61/106. 2006. Available online: https:/ / www.un.org/en/development/desa/population/migration/generalassembly/docs/globalcompact/ A_RES_61_106.pdf (accessed on 7 February 2017).

6. UNESCO. Guidelines for Inclusion-Ensuring Access to Education for all Report No. ED-2004/WS/39. 2005. Available online: https:/ / unesdoc.unesco.org/ark:/48223/pf0000140224 (accessed on 7 February 2017).

7. Georgsdottir, A.S.; Getz, I. How Flexibility Facilitates Innovation and Ways to Manage it in Organizations. Creat. Innov. Manag. 2004, 13, 166-175. [CrossRef]

8. Ajzen, I. From intentions to actions: A Theory of Planned Behavior. In Action Control: From Cognition to Behavior; Kuhl, J., Beckmann, J., Eds.; Springer: Berlin/Heidelberg, Germany, 1985; pp. 11-39. ISBN 978-3-642-69746-3.

9. Ajzen, I. Attitudes, Personality and Behavior, 2nd ed.; Open University Press: Maidenhead, Berkshire, UK, 2005; ISBN 978-0335217038. 
10. Hornby, G. Inclusive Special Education: Evidence-Based Practices for Children with Special Needs and Disabilities; Springer: New York, NY, USA, 2014; ISBN 978-1-4939-1483-8.

11. Wei, X.; Yu, J.W.; Shaver, D. Longitudinal Effects of ADHD in Children with Learning Disabilities or Emotional Disturbances. Except. Child. 2014, 80, 205-219. [CrossRef]

12. Walker, A.; Nabuzoka, D. Academic Achievement and Social Functioning of Children with and Without Learning Difficulties. Educ. Psychol. 2007, 27, 635-654. [CrossRef]

13. Montague, M. Cognitive strategy instruction in mathematics for students with learning disabilities. J. Learn. Disabil. 1997, 30, 164-177. [CrossRef]

14. Dodge, K.A. Behavioral Antecedents of Peer Social Status. Child Dev. 1983, 54, 1386. [CrossRef]

15. Malecki, C.K.; Elliot, S.N. Children's social behaviors as predictors of academic achievement: A longitudinal analysis. Sch. Psychol. Q. 2002, 17, 1-23. [CrossRef]

16. Gaastra, G.F.; Groen, Y.; Tucha, L.; Tucha, O. Unknown, Unloved? Teachers' Reported Use and Effectiveness of Classroom Management Strategies for Students with Symptoms of ADHD. Child Youth Care Forum 2020, 49, 1-22. [CrossRef]

17. Owens, J.S.; Holdaway, A.S.; Smith, J.; Evans, S.W.; Himawan, L.K.; Coles, E.K.; Girio-Herrera, E.; Mixon, C.S.; Egan, T.E.; Dawson, A.E. Rates of Common Classroom Behavior Management Strategies and Their Associations with Challenging Student Behavior in Elementary School. J. Emot. Behav. Disord. 2018, 26, 156-169. [CrossRef]

18. Monsen, J.J.; Ewing, D.L.; Kwoka, M. Teachers' attitudes towards inclusion, perceived adequacy of support and classroom learning environment. Learn. Environ. Res. 2014, 17, 113-126. [CrossRef]

19. van Mieghem, A.; Verschueren, K.; Petry, K.; Struyf, E. An analysis of research on inclusive education: A systematic search and meta review. Int. J. Incl. Educ. 2020, 24, 675-689. [CrossRef]

20. de Boer, A.; Pijl, S.J.; Minnaert, A. Regular primary schoolteachers' attitudes towards inclusive education: A review of the literature. Int. J. Incl. Educ. 2011, 15, 331-353. [CrossRef]

21. Lübke, L.; Pinquart, M.; Schwinger, M. How to measure teachers' attitudes towards inclusion: Evaluation and validation of the Differentiated Attitudes Towards Inclusion Scale (DATIS). Eur. J. Spec. Needs Educ. 2019, 34, 297-311. [CrossRef]

22. Savolainen, H.; Engelbrecht, P.; Nel, M.; Malinen, O.-P. Understanding teachers' attitudes and self-efficacy in inclusive education: Implications for pre-service and in-service teacher education. Eur. J. Spec. Needs Educ. 2012, 27, 51-68. [CrossRef]

23. Ajzen, I. The theory of planned behavior. Organ. Behav. Hum. Decis. Process. 1991, 50, 179-211. [CrossRef]

24. Künsting, J.; Neuber, V.; Lipowsky, F. Teacher self-efficacy as a long-term predictor of instructional quality in the classroom. Eur. J. Psychol. Educ. 2016, 31, 299-322. [CrossRef]

25. Skaalvik, E.M.; Skaalvik, S. Dimensions of teacher self-efficacy and relations with strain factors, perceived collective teacher efficacy, and teacher burnout. J. Educ. Psychol. 2007, 99, 611-625. [CrossRef]

26. Skaalvik, E.M.; Skaalvik, S. Teacher self-efficacy and teacher burnout: A study of relations. Teach. Teach. Educ. 2010, 26, 1059-1069. [CrossRef]

27. Gibson, S.; Dembo, M.H. Teacher efficacy: A construct validation. J. Educ. Psychol. 1984, 76, 569-582. [CrossRef]

28. Ajzen, I.; Gilbert Cote, N. Attitudes and the prediction of behavior. In Attitudes and Attitude Change; Crano, W.D., Prislin, R., Eds.; Psychology Press: New York, NY, USA, 2008; pp. 289-311. ISBN 9781138010017.

29. Schmidt, M.; Vrhovnik, K. Attitudes of teachers towards the inclusion of children with special needs in primary and secondary schools. Hrvat. Rev. Za Rehabil. Istraz. 2015, 51, 16-30.

30. Kim, H.W.; Kankanhalli, A. Investigating User Resistance to Information Systems Implementation: A Status Quo Bias Perspective. MIS Q. 2009, 33, 567. [CrossRef]

31. Marakas, G.M.; Hornik, S. Passive resistance misuse: Overt support and covert recalcitrance in IS implementation. Eur. J. Inf. Syst. 1996, 5, 208-219. [CrossRef]

32. Chhabra, S.; Srivastava, R.; Srivastava, I. Inclusive Education in Botswana: The Perceptions of School Teachers. J. Disabil. Policy Stud. 2010, 20, 219-228. [CrossRef]

33. Ekstrom, R.B. Teacher Aptitudes, Knowledge, Attitudes, and Cognitive Style as Predictors of Teaching Behavior. J. Teach. Educ. 1976, 27, 329-331. [CrossRef]

34. Ajzen, I. The Theory of Planned Behavior. In Handbook of Theories of Social Psychology: Volume 1; van Lange, P., Kruglanski, A., Higgins, E., Eds.; SAGE Publications Ltd.: London, UK, 2012; pp. 438-459. ISBN 9780857029607.

35. Statistisches Bundesamt. Lehrkräfte Nach Schularten und Beschäftigungsumfang. Available online: https://www.destatis. de/DE/Themen/Gesellschaft-Umwelt/Bildung-Forschung-Kultur/Schulen/Tabellen/allgemeinbildende-beruflicheschulenlehrkraefte.html (accessed on 3 April 2021).

36. Hossiep, R.; Paschen, M.; Hossiep, R.; Paschen, M. Das Bochumer Inventar zur Berufsbezogenen Persönlichkeitsbeschreibung: BIP; Hogrefe: Göttingen, Germany, 2003.

37. Lübke, L.; Meyer, J.; Christiansen, H. Effekte von Einstellungen und subjektiven Erwartungen von Lehrkräften: Die Theorie des geplanten Verhaltens im Rahmen schulischer Inklusion. Empir. Sonderpädag. 2016, 225-238.

38. Hattie, J. Visible Learning: A Synthesis of over 800 Meta-Analyses Relating to Achievement; Routledge: London, UK, 2009; ISBN 9780415476188.

39. Moosbrugger, H.; Kelava, A. Testtheorie und Fragebogenkonstruktion; Springer: Berlin/Heidelberg, Germany, 2020; ISBN 978-3-662-61531-7. 
40. Geiser, C. Data analysis with Mplus; The Guilford Press: New York, NY, USA; London, UK, 2013 ; ISBN 9781462502455.

41. Wilson, C.; Woolfson, L.M.; Durkin, K.; Elliott, M.A. The impact of social cognitive and personality factors on teachers' reported inclusive behaviour. Br. J. Educ. Psychol. 2016, 86, 461-480. [CrossRef]

42. Field, A. Discovering Statistics Using IBM SPSS Statistics, 5th ed.; Sage: London, UK, 2020; ISBN 978-1-5264-1952-1.

43. Fröber, K.; Dreisbach, G. Keep flexible-Keep switching! The influence of forced task switching on voluntary task switching. Cognition 2017, 162, 48-53. [CrossRef]

44. Emmer, E.T.; Stough, L.M. Classroom Management: A Critical Part of Educational Psychology, With Implications for Teacher Education. Educ. Psychol. 2001, 36, 103-112. [CrossRef]

45. Goetze, H. Regelschullehrer in Integrationsklassen mit verhaltensgestörten Schülern-eine Literaturübersicht. Heilpädag. Forsch. 1991, 2, 80-87.

46. Calderón, A.; Martínez de Ojeda, D.; Valverde, J.J.; Méndez-Giménez, A. Ahora nos ayudamos más: Docencia compartida y clima social de aula. Experiencia con el modelo de Educación. Deportiva. Rev. Int. Cienc. Deporte 2016, 12, 121-136. [CrossRef]

47. Margraf, H.; Pinquart, M. Attainment of developmental tasks in emotionally and behaviourally disturbed adolescents across regular vs. special schools: A four-group comparison. Eur. J. Spec. Needs Educ. 2015, 30, 351-366. [CrossRef]

48. Sannen, J.; de Maeyer, S.; Struyf, E.; de Schauwer, E.; Petry, K. Connecting teacher collaboration to inclusive practices using a social network approach. Teach. Teach. Educ. 2021, 97, 103182. [CrossRef]

49. Li, K.M.; Cheung, R.Y.M. Pre-service Teachers' Self-efficacy in Implementing Inclusive Education in Hong Kong: The Roles of Attitudes, Sentiments, and Concerns. Int. J. Disabil. Dev. Educ. 2021, 68, 259-269. [CrossRef]

50. Urton, K.; Wilbert, J.; Hennemann, T. Der Zusammenhang zwischen der Einstellung zur Integration und der Selbstwirksamkeit von Schulleitungen und deren Kollegien. Empir. Sonderpädag. 2014, 6, 3-16.

51. Ahmmed, M.; Sharma, U.; Deppeler, J. Variables affecting teachers' attitudes towards inclusive education in Bangladesh. J. Res. Spec. Educ. Needs 2012, 12, 132-140. [CrossRef]

52. MacFarlane, K.; Woolfson, L.M. Teacher attitudes and behavior toward the inclusion of children with social, emotional and behavioral difficulties in mainstream schools: An application of the theory of planned behavior. Teach. Teach. Educ. 2013, 29, 46-52. [CrossRef] 